\title{
Duelo y narración en Walter Benjamin: Una lectura desde el país de los desaparecidos
}

Mourning and Storytelling in Walter Benjamin: A Reading from the Country of the Lost Ones

Rita Guidarelli Mattioli Gutiérrez

Universidad Nacional Autónoma de México ritaguidarelli@gmail.com

DOI: http://doi.org/10.15366/bp2019.21.010

Bajo Palabra. II Época. No21. Pgs: 175-184 
Licenciada en etnología por la ENAH y maestra en filosofía por la UNAM, ambas con mención honorífica. Actualmente estudia el doctorado en filosofía en la Universidad Nacional Autónoma de México (UNAM), donde realiza la tesis "Juego, infancia y rememoración en Walter Benjamin: la mirada infantil como gesto filosófico”, bajo la dirección de la Dra. Silvana Rabinovich. Sus intereses académicos se centran en el juego y, recientemente, lo infantil, así como la Teoría Crítica y, en particular, la filosofía de Walter Benjamin.

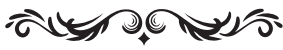

\section{Resumen}

En "Desenterrar y recordar" Walter Benjamin se acerca al tema del recuerdo desde una metáfora singular: la excavación. Mas, lejos de ser solamente una actividad del orden de lo metafórico, excavar es en ocasiones la acción literal que ha de llevarse a cabo para encontrar pistas o claves que permitan resolver enigmas contemporáneos. En México, país donde —a partir del año 2007los desaparecidos suman más de treinta mil, hombres y mujeres se han convertido en tiempos recientes en excavadores que, removiendo la tierra suelta, buscan sin descanso huellas o rastros de sus seres queridos. El saldo de la búsqueda ha sido de casi 1200 fosas clandestinas y más de tres mil cadáveres inhumados. ¿Qué hacer, pues, frente a tanta barbarie? Quizás acercándonos a la idea de narración de Benjamin, nos sea posible pensar el recuerdo en tanto desenterramiento como posibilidad de duelo en el país de los desaparecidos.

Palabras Clave: Walter Benjamin, recuerdo, excavación, narración, duelo.

\section{Abstract}

In "Excavation and Memory" Walter Benjamin approaches the subject of remembering from a specific metaphor: excavation. But far from being only a metaphoric activity, excavation is sometimes the literal action with which to find clues to solve contemporary mysteries. In Mexico, country where since 2007 there are more than thirty thousand lost people, men and women have become recently excavators who, through loose soil, search without rest for footprints or traces of their loved ones. What is to be done with so much barbarity? Perhaps through the Benjamin's notion of storytelling we could think of remembering in terms of unearthing as a possibility for mourning in the country of the lost ones.

Keywords: Walter Benjamin, remembering, excavation, storytelling, mourning. 
$\mathrm{E}$ n "Desenterrar y recordar", texto brevísimo de 1932, Walter Benjamin se acerca al tema del recuerdo desde una metáfora singular: la excavación. Emparentado con la arqueología, el retorno a lo acontecido se presenta como una tarea de desenterramiento que, palada tras palada, trae a la superficie imágenes de un pasado sepultado. Mas lejos de ser solamente una actividad del orden de lo metafórico, excavar es en ocasiones la acción literal que ha de llevarse a cabo para encontrar pistas o claves que permitan resolver enigmas contemporáneos.

En México, país donde - a partir del año 2007- las personas desaparecidas suman más de treinta mil, hombres y mujeres se han convertido en excavadores que, removiendo la tierra suelta, buscan sin descanso huellas, rastros de sus seres queridos. El saldo de la búsqueda ha sido de casi 1200 fosas clandestinas y más de tres mil cadáveres inhumados. ${ }^{1}$ Ante un panorama tan desolador y tan tinto de desesperanza, surge una pregunta irremediable: ¿Qué hacer con todo esto? Es decir, ¿qué hacer con los restos una vez que han sido desenterrados? ¿Qué hacer con los fragmentos, con los retazos de pasado que, sea en sentido literal o figurado, se han descubierto durante la excavación y que afloran como imágenes llenándolo todo? ¿Qué hacer, pues, frente a tanta barbarie?

En lo que sigue intentaremos acercarnos a la idea benjaminiana de narración, pues quizá desde allí podamos pensar el recuerdo-desenterramiento como posibilidad de duelo en el país de los desaparecidos.

\section{Primera palada}

LA NEGACIÓN DEL DUELO, simbolizado en los ritos funerarios, ha sido un tema frecuente de la literatura. En la épica griega se manifiesta en los últimos cantos de la Ilíada, tras el enfrentamiento de Aquiles con Héctor, que culmina con la muerte del troyano. Debido a su dolorosa furia ante la pérdida de Patroclo a manos de Héctor, Aquiles se propone deshonrar al héroe de Troya de la peor manera: negándole el derecho al ritual del luto que exigen los dioses. Después de derrotarlo, amarra el cuerpo de Héctor a su carro y lo arrastra boca abajo desde el lugar del

\footnotetext{
${ }^{1}$ Comisión Nacional de Derechos Humanos (CNDH), Informe especial sobre desaparición de personas y fosas clandestinas en México, Ciudad de México, 2017, disponible en <http://www.cndh.org.mx/sites/all/doc/Informes/ Especiales/InformeEspecial_20170406_Resumen.pdf>.
} 
combate hasta donde se encuentran las naves aqueas. Durante once días continúa ultrajando el cadáver, dándole vueltas alrededor del túmulo. Y nada lo habría hecho cambiar de opinión si Príamo, rey de Troya, bajo resguardo divino, no se hubiera acercado a hurtadillas a su nave para rogarle compasión y que le devolviera el cuerpo de su hijo. Nueve días le pide para llorarlo en el palacio y dos días más para celebrar un banquete en honor del muerto y erigir su tumba; "al duodécimo - continúa Príamo- entablaremos combate si es preciso". ${ }^{2}$ Y así, el relato épico de la guerra de Troya no cierra con la caída de la ciudad amurallada, que se sabe inminente, sino con el recuento de los funerales de Héctor, domador de caballos.

En la literatura griega, hay otra obra donde esta experiencia se expresa todavía de manera más emblemática. Nos referimos a Antígona, una de las tragedias de Sófocles. Allí se narra la historia de una mujer, hija de Edipo, cuyos hermanos han muerto en combate uno frente al otro. Creonte, su tío, ha decretado que a uno de ellos, Eteocles, defensor de Tebas, se le dé digna sepultura; mientras que el otro, Polinices, habrá de recibir el trato de un traidor. Así lo dicta Creonte: "que ninguno le tribute los honores postreros con un enterramiento, ni le llore. Que se le deje sin sepultura y que su cuerpo sea pasto de las aves de rapińa y de los perros, y ultraje para la vista". ${ }^{3}$ Antígona, desesperada ante la pérdida de sus hermanos y la deshonra a los dioses, decide enterrar a Polinices aun a costa de su propia vida. Se acerca a escondidas al cadáver y lo cubre de tierra, preparándolo para los ritos correspondientes. Su tío decreta entonces que Antígona sea enterrada viva, por transgredir las normas de los hombres y de la ciudad para cumplir, en cambio, con lo prescrito por la tradición.

En México hay hoy innumerables Príamos y Antígonas, mujeres y hombres que buscan a sus seres queridos para darles la sepultura que merecen; para terminar con la incertidumbre y comenzar, por fin, el proceso de luto que hasta ahora les ha sido negado. Así se muestra en el reclamo expresado en Antígona González, una versión moderna de la antigua tragedia, ubicada en el contexto de la desaparición de personas que azota a nuestro país: "Ellos dicen que sin cuerpo no hay delito. Yo les digo que sin cuerpo no hay remanso, no hay paz posible para este corazón. Para ninguno". ${ }^{4} \mathrm{Y}$ es que, a diferencia de la heroína griega, quienes aquí reclaman el derecho al duelo han de llevar a cabo antes la búsqueda de sus seres queridos; han de realizar primero, nos dice la autora, "la absurda, la impostergable labor de desenterrar un cuerpo para volver a enterrarlo. Para confirmar en voz alta lo tan

\footnotetext{
${ }^{2}$ Homero, Ilíada, Madrid, Gredos, 2015, p. 505, v. 667.

3 Sófocles, "Antígona", en Tragedias, Madrid, Gredos, 2015, pp. 144-145, v. 203-207.

${ }^{4}$ Uribe, S., Antígona González, Oaxaca, Sur+, 2012, p. 24.
} 
temido, lo tan deseado: sí, señor agente, sí, señor forense, sí, señor policía, este cuerpo es mío". 5

A través de la obra de Sara Uribe acompañamos el dolor de su protagonista: Sandra Muñoz, cuyo hermano, Tadeo, ha desaparecido. Haciendo eco de las palabras de otros, del dolor compartido por tantos, de —en palabras de la autora - "todos esos duelos que se esconden tras los rostros de las personas que nos topamos", ${ }^{6}$ nos enfrentamos a la tristeza gigantesca y la minúscula esperanza que representa la labor de búsqueda, la labor de excavación. "Lo queremos encontrar, aunque sea muertito — dicen los familiares de los desaparecidos- Necesitamos sepultarlo, llevarle flores, rezarle una oración". 7 "Nuestro corazón pide que no aparezcan — continúan—, pero si nos entregaran sus cuerpos por fin descansaríamos". ${ }^{8}$ Pues la desaparición de un ser querido, la pregunta constante por lo que ha podido ocurrirle, no es propiamente vida. Así lo describe Uribe:

Somos lo que deshabita desde la memoria. Tropel. Estampida. Inmersión. Diáspora. Un agujero en el bolsillo. Un fantasma que se niega a abandonarte. Nosotros somos esa invasión. Un cuerpo hecho de murmullos. Un cuerpo que no aparece, que nadie quiere nombrar. Aquí todos somos limbo. ${ }^{9}$

\section{Segunda palada}

EN UN ARTículo de I9I 5 (aunque publicado dos años más tarde), Sigmund Freud se dio a la tarea de reflexionar en torno al duelo y la melancolía. El duelo, escribe entonces el psicoanalista vienés, es un afecto normal que aparece "frente a la pérdida de una persona amada o de una abstracción que haga sus veces, como la patria, la libertad, un ideal, etc.".${ }^{10}$ Lo caracteriza el desencantamiento, la indiferencia frente a los sucesos del mundo exterior, de todo aquello que no tenga relación alguna con la memoria del fallecido. "En el duelo — resume Freud_-, el mundo se ha vuelto pobre y vacío". ${ }^{11}$

\footnotetext{
5 Ibíd., p. 75.

${ }^{6}$ Ibíd., p. 53.

7 Ibid., p. 81.

8 Ibíd., p. 84.

9 Ibíd., p. 73.

${ }_{10}$ Freud, S., "Duelo y melancolía”, en Obras completas, Buenos Aires, Amorrortu, 1992, Volumen XIV, p. 241.

11 Ibíd., p. 243.
} 
Casi un par de décadas más tarde (en 1933), Walter Benjamin escribió "Experiencia y pobreza". Allí habla también de la pérdida de sentido del mundo, del empobrecimiento en términos de experiencia comunicable, de la incapacidad de narrar; en suma, de la intransmisibilidad de lo que, hasta antes de la primera guerra mundial, conformaba la tradición: un conjunto de experiencias comunes susceptibles de ser compartidas de boca en boca. A esta devaluación de la experiencia Benjamin la identifica como una nueva barbarie. ${ }^{12}$

Dicha barbarie se muestra ante nuestros ojos con un halo similar al de la que actualmente se vive en México. Como aquélla, la nuestra se desenvuelve también alrededor del silencio. El silencio de los desaparecidos. El silencio de sus familiares, enmudecidos por el miedo. El silencio de las autoridades, que con frecuencia acallan los rastros de las víctimas y las pistas que señalan a los responsables. Este silencio, que impide la narración de la experiencia como relato, se vincula de igual modo con la imposibilidad de recordar. Quizás a eso se refiera Freud con el término trauma y a eso aluda Benjamin cuando recupera de Baudelaire la palabra shock. Pues ambos sucesos, nos dice Jeanne-Marie Gagnebin, "producen una doble incapacidad: la de recordar y la de contar, según un orden coherente y totalizador, de acuerdo con un orden de producción de sentido". ${ }^{13}$

Si la palabra ha sido silenciada; si, como piensa Benjamin, "la cotización de la experiencia se ha venido abajo" ${ }^{14}$ y se ha vuelto imposible intercambiar historias, ¿qué queda, pues, por hacer de cara a esta nueva barbarie?

En opinión de Freud, el duelo ha de entenderse como un trabajo, una labor inconsciente que posibilita el "remplazo" del antiguo objeto (es decir, de la persona amada) por uno nuevo. ${ }^{15}$ En contraste, para Jean Allouch el duelo es acto, "capaz de efectuar en el sujeto una pérdida sin compensación alguna, una pérdida a secas". ${ }^{16}$ Así pues, lo que para Freud es proceso interrumpido, duelo patológico o no resuelto, a ojos del psicoanalista francés es otra forma de experimentar la pérdida, de atravesar el duelo, de continuar viviendo. ${ }^{17}$ En cualquier caso, la nueva noción

12 Benjamin, W., "Experiencia y pobreza”, en Obras, libro II, vol. 1, Madrid, Abada, 2010, p. 218. El énfasis es nuestro.

13 Gagnebin, J.M., "Narración”, en Esther Cohen (ed.), Glosario Walter Benjamin. Conceptos y figuras, Ciudad de México, unam, 2016, p. 154.

14 Benjamin, "Experiencia y pobreza”, p. 217.

15 Freud, S., "Duelo y melancolía”, op. cit., p. 250.

${ }^{16}$ Allouch, J., Erótica del duelo en tiempos de la muerte seca, Buenos Aires, El cuenco de plata, 2011, p. 9.

17 "Mi cuestionamiento del duelo encontró pues su punto de partida en esta constatación: había un duelo incluso allí donde se decía que no lo había, y se lamentaba que no hubiese duelo cuando se lo estaba aguardando. Y a veces se llegaba incluso hasta esforzarse en hacer que hicieran su duelo (pero tal como se lo concebía) aquellos mismos que lo hacían (aunque a su manera)”. Ibíd., p. 18. 
de barbarie de la que habla Benjamin tiene un lado positivo, que aparece como respuesta a otra interrogante: “¿Adónde lleva al bárbaro esa su pobreza de experiencia? A comenzar de nuevo y desde el principio, a tener que arreglárselas con poco, a construir con poco y mirando siempre hacia delante". ${ }^{18}$

\section{Tercera palada}

La REFLeXión de WaLter Benjamin en torno a la experiencia y su empobrecimiento está ligada íntimamente a la inquietud ante el ocaso de la narración. La atrofia de la experiencia se manifiesta, como se ha dicho, en la imposibilidad de transmitirla. Pobreza de experiencia es, así, a juicio del filósofo, incapacidad de intercambiar historias; inhabilidad para escuchar, recordar, narrar. "Narrar historias — nos dice Benjamin — siempre ha sido el arte de seguir contándolas, y este arte se pierde si ya no hay capacidad de retenerlas". ${ }^{19}$

No obstante, lejos de ser expresión de un anhelo nostálgico que pretenda restaurar los modos antiguos de la tradición oral o sus contextos (como el taller artesanal o el tiempo del tejido y el bordado), en el lamento benjaminiano de lo que se trata más bien, de acuerdo con Gagnebin, es de inventar otras formas de memoria y narración. ${ }^{20}$ Desde su perspectiva, al filósofo berlinés le interesa la búsqueda de otra historiografía, otra transmisión de la historia; la búsqueda, en su expresión, "de una nueva narratividad, una narración a partir de las migajas y los escombros de la narrativa tradicional". ${ }^{21} \mathrm{Y}$ es que el asunto de la oralidad que tanto aqueja a Benjamin tiene que ver con nuestra manera de concebir el tiempo. "El problema de la narración — apunta Gagnebin - desemboca en el de nuestra percepción del pasado y del futuro, es decir, en la pregunta por cómo podemos - o no- transformar nuestro presente histórico". ${ }^{22}$

Pero, ¿cómo es que la narración alcanza un lugar tan importante en el pensamiento benjaminiano? ¿Por qué algo tan sencillo y cotidiano como el intercambio de experiencias, esa "facultad que — como diría el filósofo— nos pareciera inalienable, la más segura entre las seguras", ${ }^{23}$ tiene que ver con la posibilidad de vislumbrar

\footnotetext{
${ }^{18}$ Benjamin, W., "Experiencia y pobreza”, op. cit., p. 218.

${ }_{19}$ Benjamin, W., "El narrador", en Iluminaciones IV. Para una critica de la violencia y otros ensayos, Madrid, Taurus, 2001, p. 118.

${ }^{20}$ Gagnebin, J.M., “Narración”, op. cit., p. 158.

21 Ibíd., p. 155.

22 Ibíd., p. 156.

23 Benjamin, W., “El narrador”, op. cit., p. 112.
} 
otros mundos posibles? Quizá las siguientes palabras de Benjamin nos ayuden a comprenderlo mejor: "Pues allí donde impera la experiencia en su sentido estricto, ciertos contenidos que son propios de nuestro pasado individual entran finalmente en conjunción con los del colectivo en la memoria". ${ }^{24}$

Ahí radica la singularidad del narrador en tanto figura emblemática, que - según nos cuenta Benjamin - "toma lo que narra de la experiencia; la suya propia o la transmitida. Y la torna, a su vez, en experiencia de aquellos que escuchan su historia”. ${ }^{25}$ En ese sentido, como advierte Alessandro Baricco leyendo a Benjamin en El narrador, nuestro filósofo relaciona la narración con un cierto estar en el mundo, con un cierto caminar por la vida. ${ }^{26} \mathrm{Y}$ así, en ese andar, el narrador aprende muchos consejos. Mas, como el sabio, sus lecciones no sirven sólo para unos cuantos, sino para muchos o, mejor aún, para todos. Pues "el narrador — nos dice el escritor italiano - no busca el sentido de la vida, sino más bien la moraleja de la historia. No busca el sentido de una vida, sino la moraleja de todas las vidas posibles". ${ }^{27}$

Algo similar ocurre con los buscadores de desaparecidos en nuestro país, detectives de historias interrumpidas, ocultas y olvidadas bajo varias capas de tierra, desmembradas y convertidas en fragmento. "Yo quiero la verdad, la memoria, la justicia y la no repetición — dice Araceli Rodríguez al compartir su experiencia de madre en búsqueda de un hijo desaparecido- Q Que lo que yo vivo no lo viva nadie más". ${ }^{28}$ Esas palabras se repiten en los testimonios de muchos de ellos, que, en cuanto narradores, buscan e intercambian experiencias, aprendizajes, intuiciones. Porque saben que sólo así, compartiendo sus historias, advirtiéndonos a través de sus relatos, lo que parece una vivencia individual se muestra como lo que en verdad es: una experiencia compartida por muchos, demasiados; un recuerdo colectivo; esto es, memoria.

Y así, por medio de la narración (que, en sentido amplio, es más que oralidad; que, como el duelo, es también acto), nuestras Antígonas y nuestros Príamos hacen de la excavación un ejercicio del recuerdo en el país de los desaparecidos. Y justo así, excavando y recordando, narran (en términos benjaminianos) "su vida y su dignidad; la totalidad de su vida" ${ }^{29} \mathrm{Y}$ con ella, narran también nuestra historia, la historia de todos, entretejida con el hilo sutil de la esperanza.

\footnotetext{
${ }^{24}$ Benjamin, W., "Sobre algunos motivos en Baudelaire", en Baudelaire, Madrid, Abada, 2014, p. 159.

${ }^{25}$ Benjamin, W., "El narrador", op. cit., p. 115.

${ }^{26}$ Baricco, A., apud. Benjamin, W., Il narratore. Considerazioni sull'opera di Nikolai Leskov, Turín, Einaudi, 2011p. 11. Las traducciones de este texto son nuestras.

${ }^{27}$ Ibíd., p. 69.

${ }^{28}$ Periodistas de a Pie, Buscadores: Araceli Rodríguez, México, 2017. Disponible en: http://piedepagina.mx/buscadores/araceli-rodriguez.php.

29 Benjamin, W., "El narrador", op. cit., p. 134.
} 


\section{Referencias Bibliográficas}

Allouch, Jean. Erótica del duelo en tiempos de la muerte seca, Tr. Silvio Mattoni, Buenos Aires, El cuenco de plata, 2011.

Benjamin, Walter. "Sobre algunos motivos en Baudelaire", en Baudelaire, Tr. Alfredo Brotons Muñoz, Madrid, Abada, 2014, pp. 151-205.

- Il narratore. Considerazioni sull'opera di Nikolai Leskov, ed. comentada por Alessandro Baricco, tr. Renato Solmi, Turín, Einaudi, 2011.

- "Experiencia y pobreza", en Obras, libro II, vol. 1, Tr. Jorge Navarro Pérez, Madrid, Abada, 2010, pp. 216-222.

- "El narrador", en Iluminaciones IV. Para una crítica de la violencia y otros ensayos, Tr. Roberto Blatt, Madrid, Taurus, 2001, pp. 111-134.

Comisión Nacional de los Derechos Humanos (CNDH). "Resumen ejecutivo del Informe especial sobre desaparición de personas y fosas clandestinas en México", México, 6 de abril de 2017, disponible en: http://www.cndh.org.mx/sites/all/ doc/Informes/Especiales/InformeEspecial_20170406_Resumen.pdf [fecha de consulta: 10 de abril de 2017].

Freud, Sigmund. "Duelo y melancolía”, en Obras completas, Tr. José L. Etcheverry, Buenos Aires, Amorrortu, 1992, Volumen XIV, pp. 235-258.

Gagnebin, Jeanne-Marie. "Narración”, en Esther Cohen (ed.), Glosario Walter Benjamin. Conceptos y figuras, Ciudad de México, unam, 2016, pp. 153-162.

Homero. Ilíada, Tr. E. Crespo, col. Biblioteca Clásica, Madrid, Gredos, 2015.

Periodistas de a Pie, Buscadores: Araceli Rodríguez, México, 2017. Disponible en http://piedepagina.mx/buscadores/araceli-rodriguez.php [fecha de consulta: 10 de abril de 2017].

Sófocles. "Antígona", en Tragedias, Tr. A. Alamillo, col. Biblioteca Clásica, Madrid, Gredos, 2015, pp. 127-187.

Uribe, Sara. Antígona González, Oaxaca, Sur+, 2012. Disponible en formato PDF en https://poesiamexa.files.wordpress.com/2016/06/antc3adgona-gonzc3a1lez.pdf.

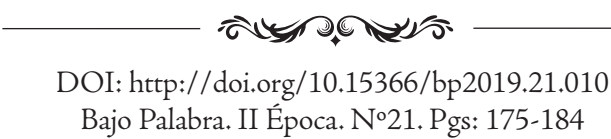


